\title{
Physiology of Nitric Oxide in the Respiratory System
}

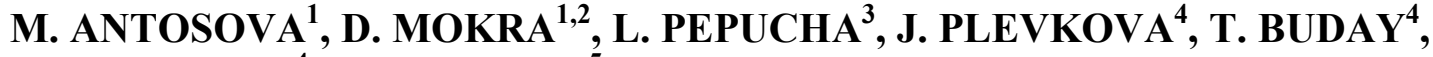 \\ M. STERUSKY ${ }^{4}$ A. BENCOVA ${ }^{5}$
}

${ }^{1}$ Biomedical Center Martin, Jessenius Faculty of Medicine in Martin, Comenius University in Bratislava, Martin, Slovakia, ${ }^{2}$ Department of Physiology, Jessenius Faculty of Medicine in Martin, Comenius University in Bratislava, Martin, Slovakia, ${ }^{3}$ Research Centre, University of Zilina, Zilina, Slovakia, ${ }^{4}$ Department of Pathophysiology, Jessenius Faculty of Medicine in Martin, Comenius University in Bratislava, Martin, Slovakia, ${ }^{5}$ Clinic of Pneumology and Phthisiology, Jessenius Faculty of Medicine in Martin, Comenius University in Bratislava and University Hospital Martin, Martin, Slovakia

Received April 30, 2017

Accepted April 30, 2017

\section{Summary}

Nitric oxide (NO) is an important endogenous neurotransmitter and mediator. It participates in regulation of physiological processes in different organ systems including airways. Therefore, it is important to clarify its role in the regulation of both airway and vascular smooth muscle, neurotransmission and neurotoxicity, mucus transport, lung development and in the surfactant production. The bioactivity of NO is highly variable and depends on many factors: the presence and activity of NO-producing enzymes, activity of competitive enzymes (e.g. arginase), the amount of substrate for the NO production, the presence of reactive oxygen species and others. All of these can change NO primary physiological role into potentially harmful. The borderline between them is very fragile and in many cases not entirely clear. For this reason, the research focuses on a comprehensive understanding of NO synthesis and its metabolic pathways, genetic polymorphisms of NO synthesizing enzymes and related effects. Research is also motivated by frequent use of exhaled NO monitoring in the clinical manifestations of respiratory diseases. The review focuses on the latest knowledge about the production and function of this mediator and understanding the basic physiological processes in the airways.

\section{Key words}

Nitric oxide • Nitric oxide synthase - Respiratory system • Physiology

\section{Corresponding author}

M. Antosova, Biomedical Center Martin, Division of Respirology, Malá Hora 4C, 03601 Martin, Slovakia. E-mail: antosova@jfmed.uniba.sk

\section{Introduction}

The small and simple molecule nitric oxide (NO) was considered an environmental pollutant for a long time. This opinion has changed with the discovery of its role as a relaxing factor derived from endothelium (Furchgott and Zawadzki 1980, Púszerová et al. 2010). A number of positive and negative effects of NO have been reported in all systems including respiratory system since then (Ricciardolo 2003). Detection of exhaled NO is nowadays a validated method, which belongs to standard protocols in the management of respiratory diseases, such as bronchial asthma (Prado et al. 2011) or primary ciliary dyskinesia (Djakow and O'Callaghan 2014). Numerous studies have been published to point out the role of NO in the pathogenesis of various diseases affecting respiratory system (Silkoff et al. 2000). However, this may lead to the assumption that NO has only adverse effects on human health. In fact, NO is a messenger that regulates various biological processes at low concentrations, and becomes cytotoxic at high concentrations. The main objective of this review is to 
summarize the knowledge on NO and its positive role in regulation of the airway smooth muscle tone, pulmonary blood flow, mucus output, local defensive processes and surfactant function.

\section{Nitric oxide synthesis}

Each of at least 40 different types of cells in the human respiratory system has the ability to produce $\mathrm{NO}$ through one or more isoforms of NO synthases (NOS) (Fig. 1). NO participates in a number of processes depending on the target cells by relaxing the airway and vascular smooth muscle cells, regulating phagocytosis etc. These processes are coordinated under physiological conditions to maintain optimal function of the respiratory system (Ricciardolo 2003).

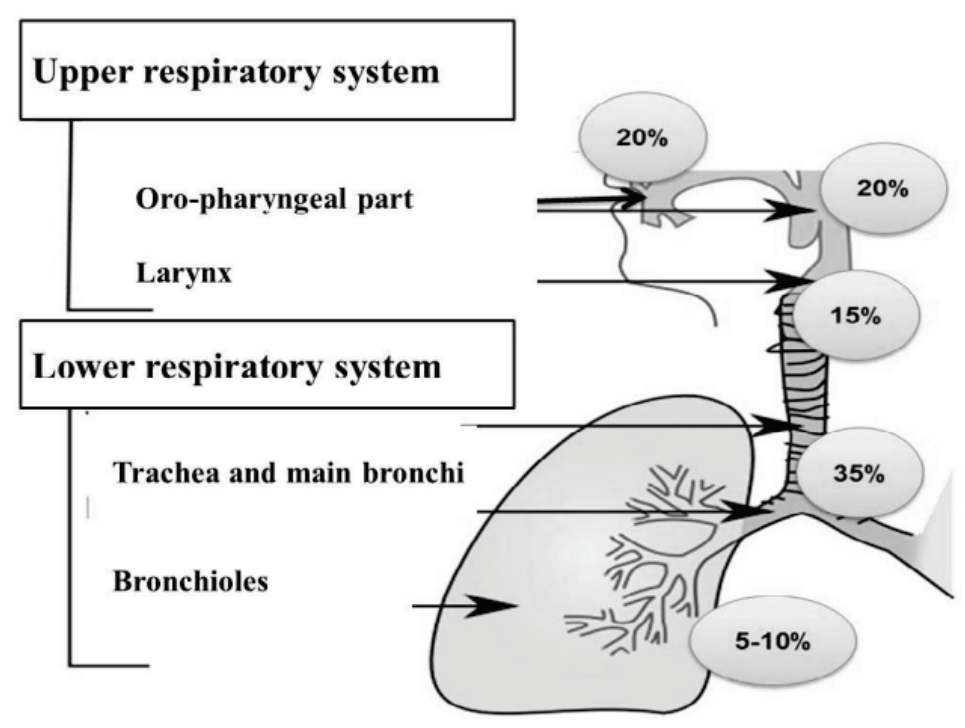

Fig. 1. Distribution of nitric oxide production in the respiratory system.

Endogenous NO is produced by NOS from the amino acid L-arginine, which is converted into NO and L-citrulline (Fig. 2). Oxidation of L-arginine has several steps. The first one is the production of $\mathrm{N} \omega$-hydroxy-Larginine (NOHA), which is followed by oxidative cleavage of the $\mathrm{C}=\mathrm{N}$ bond in NOHA into $\mathrm{NO}$ and L-citrulline, which is then recycled back to the L-arginine in a process referred to as citrulline/arginine cycle $(\mathrm{Wu}$ and Morris 1998). Physiological concentration of
L-arginine in the human body is sufficient for the continual production of NO (Sajeev et al. 1998). Although the catalytic activity of the NOS is relatively low (KmL-Arg 1.4 to $32.2 \mathrm{mmol} / \mathrm{l}$ ), depending on the type of isoform, supplementation of the L-arginine may partially increase the availability of NO (Su et al. 1997). $\mathrm{NO}$ can be also produced without the direct action of NOS, e.g. NOHA releases NO by interaction with cytochrome P-450 (Jia et al. 1998).

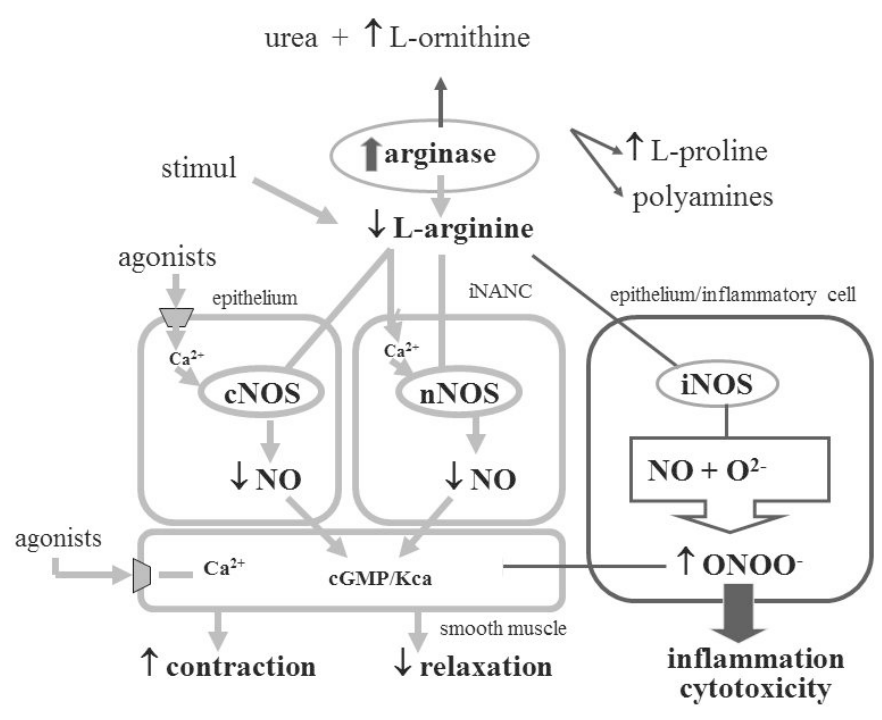

Fig. 2. Nitric oxide synthesis and basic mechanisms of NO effects. NO - nitric oxide, iNANC - inhibitory non-adrenergic non-cholinergic nervous system, $\mathrm{Ca}^{2+}$ - calcium, cNOS - constitutive nitric oxide synthase, nNOS - neuronal nitric oxide synthase, iNOS - inductive nitric oxide synthase, cGMP - cyclic guanosine monophosphate, $\mathrm{KCa}$ - potassium dependent ion channels, $\mathrm{ONOO}^{-}$- peroxynitrite, $\mathrm{O}^{2-}-$ superoxide. 
There are three isoforms of NOS in the human body and all of them were identified in the respiratory system. Neuronal NOS (nNOS) was detected in nonadrenergic non-cholinergic nervous system (NANC), airway nerves and epithelium, endothelial NOS (eNOS) is present mainly in endothelial cells of the lung vasculature. The third isoform - inductive NOS (iNOS) has been associated with the pro- and anti-inflammatory responses. All isoforms are flavoproteins that contain tetrahydrobiopterin, heme, and an area that is homologous to cytochrome P450 reductase. They act as dioxygenases using an oxygen molecule and NADPH to transform the L-arginine into L-citrulline and release the nitric oxide (Förstermann and Sessa 2012). There are specific differences for each of the NOS isoforms, not only in the term of their structure, location, but also at the transcriptional and post-translational regulation of their catalytic activity (Lacza et al. 2003). Neuronal and endothelial NOS are referred to as constitutive. Their activity depends on 6 intracellular calcium levels and they produce femto- or picomolar concentrations of $\mathrm{NO}$, which are considered to be the key regulators of homeostasis (Ricciardolo et al. 2004, Cox et al. 2009).

Neuronal NOS is localized in the cytosol of cells of the central and peripheral nervous system (Ward et al. 1995) and, in the respiratory system, it is present in the epithelium including the alveolar lining and in the nerve fibres innervating the airway structures (Cox et al. 2009). NO produced by nNOS is important inhibitory neurotransmitter of NANC participating in the control of airway smooth muscle tone via NO/cGMP mechanism. The primary process which controls activity of the enzyme is interaction of calmodulin with the calmodulinbinding domain after the increase of $\mathrm{Ca}_{\mathrm{i}}{ }^{2+}$ levels to approximately $500 \mathrm{nmol} / \mathrm{l}$. Although nNOS is described as a constitutive isoform, its expression is modulated by both physiological (estrogens), and pathological (nerve damage) stimuli (Grasemann et al. 2003).

Function of eNOS was described for the first time in the cardiovascular system. Calcium and L-arginine depending enzyme was identified in endothelial cells, wherein the NO exerts vasodilation and it is involved in the regulation of vascular tone and other processes. In the respiratory system, the eNOS is localized in the epithelium of trachea, bronchi and alveoli (Pechkovsky et al. 2002). eNOS immunoreactivity was also detected in endothelial cells of pulmonary vessels, in the nasal mucosa and in the basal membrane of ciliary microtubules, where it is thought to contribute to the regulation of ciliary movement (Xue et al. 1996, Kawamoto et al. 1998). eNOS is the enzyme with a unique membrane localization. It is located specifically in caveolae, small membrane invaginations characterized by the presence of protein caveolin. eNOS oxygenase domain contains a binding site for caveolin-1 that competes with calmodulin, leading to activation of eNOS. This process is regulated by $\mathrm{Ca}_{\mathrm{i}}{ }^{2+}$ (Kone 1999). NO release occurs in short pulses in response to the influx of $\mathrm{Ca}^{2+}$ (Fleming and Busse 2003). The expression of eNOS is affected by both physiological (hormonal) and pathological stimuli e.g. in cardiovascular diseases, chronic hypoxia or heart failure (Harrison 1997, Kone 1999).

Inductive NOS (iNOS) was for the first time detected in the alveolar macrophages, where its activity was increased in a response to proinflammatory cytokines and endotoxins. It is a cytoplasmic enzyme present in various cells. Expression of iNOS in the airways is enhanced primarily by proinflammatory cytokines such as TNF- $\alpha$, IL-1- $\beta$ and INF- $\gamma$ (Vallance 2001, Ricciardolo et al. 2004). For quite a long time, it was suggested that the source of iNOS in the respiratory system are mainly alveolar macrophages. Later, however, it was detected in the epithelium of the proximal and terminal bronchioles (Pechkovsky et al. 2002), alveolar type II cells (Warner et al. 1995), lung fibroblasts, (Romanska et al. 2002), bronchial and vascular smooth muscle (Griffith and Stuehr 1995), mast cells (Gilchrist et al. 2002), endothelial cells (Palmer et al. 1987) and neutrophils (Blackford et al. 1994). One of the best described features of iNOS is its role in the body's response to infectious agents. This effect is mediated by a number of highly reactive radicals (superoxide, peroxynitrite), which inactivate the iron-containing enzymes and modify proteins leading to cytostatic or cytotoxic effects against pathogens. The cytotoxic effect of NO against tumour cells has also been reported (Ricciardolo et al. 2004).

iNOS activity depends on binding to calmodulin. In contrast to the constitutive isoforms, this binding is independent on $\mathrm{Ca}_{\mathrm{i}}{ }^{2+}$, and occurs even at very low $\mathrm{Ca}_{\mathrm{i}}{ }^{2+}$. This results in sustained release of NO in quantities larger than physiological. In pathological conditions, the production of NO by iNOS may increase up to 1,000-times and instead of having regulatory and protective effects NO acts as a cytotoxic agent. Too high NO levels then lead to vascular smooth muscle relaxation, increase vascular permeability and mucus secretion, cause mucosal damage and modulate activity 
of immune cells controlling inflammation in the respiratory system (Meurs et al. 2003).

All three isoforms localized in the respiratory system participate in the regulation of respiratory physiology by cooperative production of NO. Any change of their activity may lead to the change of NO level and contribute to the pathogenesis of various respiratory diseases (Meurs et al. 2002, Antosova et al. 2012, Kopincova and Calkovska 2016).

L-arginine is the only substrate for NOS, and thus the regulation of L-arginine availability could determine cellular rates of NO production. L-arginine is an essential amino-acid, which is supplied by diet and actively transported into cells. L-arginine is abundant with normal dietary intake, but its availability is low due to extensive protein binding. Oral administration of L-arginine in humans is associated with increased exhaled NO and with increased concentration of nitrates in the plasma (Kharitonov et al. 1995, Antosova and Strapkova 2013).

L-arginine can be either converted by NOS to NO and citrulline, or it can be catabolized by arginase. There are two forms of arginase in human body. Arginase I is hepatic cytosolic enzyme and arginase II is extrahepatic mitochondrial enzyme (Gotoh et al. 1997, Vercelli 2003). It participates in synthesis of proline, which is a part of proteins, and polyamines controlling cellular proliferation and production of collagen (Morris 2002, Vercelli 2003). The presence of both isoforms of arginase was confirmed in the respiratory system (Vercelli 2003). Induction of any type of arginase could decrease bioavailability of L-arginine for NOS, and therefore reduce effects mediated by $\mathrm{NO}(\mathrm{Wu}$ and Morris 1998).

The NO production can be inhibited by the blockage of NOS or by the administration of an alternative substrate that inhibits the production of $\mathrm{NO}$ by these enzymes. Recently, many NO inhibitors as L-NG-monomethyl-arginine citrate (L-NMMA), L-NG-nitroarginine methyl ester (L-NAME) or L-canavanin that block the NOS have become commercially available (Prado et al. 2011, Antosova et al. 2015).

\section{Molecular effects of NO}

As mentioned above, small amounts of NO produced by constitutive forms of NOS are involved in the regulation of physiological processes, while high levels of NO possess the toxic effect (Table 1). The effects of NO are further influenced by other factors such as production rate, time of its release and the concentration of oxygen and other radicals (Morgan 2000). NO activity is classified to cGMP-dependent or cGMP-independent and many functions such as airway smooth muscle relaxation appear to utilize both pathways (Domenico 2004).

Table 1. The basic effects of nitric oxide in the respiratory system.

\begin{tabular}{ll}
\hline Physiology & Pathophysiology \\
\hline Neurotransmission (iNANC) & Bronchial hyperreactivity \\
Bronchodilation & Vasodilation \\
Surfactant production & Free radical production \\
Mucous secretion & Mucous hypersection \\
Ciliary motility stimulation & Ciliary motility inhibition \\
Antiinflammatory effect & Proinflammatory effect \\
\hline
\end{tabular}

iNANC - inhibitory non-adrenergic non-cholinergic nervous system.

\section{Effects mediated by cGMP}

Perhaps most studied is the effect of NO mediated by soluble guanylyl-cyclase. With this mechanism, NO produced by constitutive isoforms of NOS binds to the heme $\mathrm{Fe}^{2+}$ of the guanylyl-cyclase, what changes activity of this enzyme (Sajeev et al. 1998,
Morgan 2000). It results in the conversion of guanosine triphosphate to cyclic GMP, which in turn activates cGMP-dependent protein kinases (PKGs). PKGs catalyze further phosphorylation of proteins (Charles 1999), activate or inhibit certain types of ion channels or regulate the activity of phosphodiesterases. At functional 
level this results into various cellular processes such as vascular and airway smooth muscle relaxation (Carvajal et al. 2000, Vallance 2001, Hamad et al. 2003). It is known that cGMP causes the relaxation of smooth muscle by reducing $\mathrm{Ca}_{\mathrm{i}}{ }^{2+}$ or decreasing the sensitivity of the contractile system to the $\mathrm{Ca}_{\mathrm{i}}^{2+}$ (Ricciardolo et al . 2004). The effect of cGMP is modulated by the administration of compounds reducing the biodegradation of cGMP such as inhibitors of endogenous phosphodiesterases (PDEs), which may lead to the smooth muscle relaxation. Potential of these substances in respiratory system and their clinical relevance is extensively studied (Mokry and Mokra 2013).

\section{cGMP independent mechanisms}

Ion channels are transmembrane protein structures that control the transfer of ions between the cytosol and the extracellular space. They play a role in the regulation of bronchomotor tone (Abderrahmane et al. 1998) and some of them seem to be activated by NO.

NO activates potassium channel, especially highly conductive calcium-dependent $\mathrm{K}^{+}$channel $\mathrm{BKCa}$, present in the airway smooth muscle cells (Kažić and Gojković-Bukarica 1999). Consequent membrane hyperpolarization and the reduction of $\mathrm{Ca}_{\mathrm{i}}^{2+}$ concentration results in bronchodilation. Some NO donors may act by this mechanism (Stuart-Smith et al. 1998).

Under certain circumstances nitric oxide has cytotoxic effects. A key mechanism in this process is the interaction of NO with superoxide radical producing peroxynitrite (Aizawa 1999). This may be either converted to harmless nitrate, or as a strong oxidant it can lead to cellular damage. Damage is caused either directly by nitration of tyrosine, which leads to irreversible dysfunction of important proteins, or it initiates production of other reactive molecules with cellular toxicity (Cucchiaro et al. 1999, Antosova et al. 2012, Kleniewska and Goracca 2016). Peroxynitrite along with NO can also damage DNA, alter DNA repair process and trigger a cascade of events leading to cell apoptosis (Ricciardolo 2003).

By its ability to alter the structural integrity and

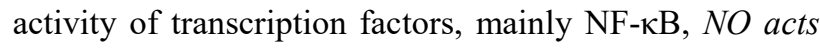
as a modulator of gene expression. NF- $\mathrm{BB}$ is a protein required for transcription of many proinflammatory molecules, enzymes, cytokines and chemokines. Activation of this factor can trigger processes involved in the iNOS expression and initiation of inflammation (Nijkamp and Folkerts 1997).

\section{The role of NO in the regulation of airway smooth muscle tone}

The regulation of bronchomotor tone is a complex physiologic process, primarily based on the activity of autonomic nervous system. In addition, bronchial tone is influenced by many humoral factors. The role of NO in this process has been extensively studied for more than 40 years. In 1968, Aviado with co-workers demonstrated that inhalation of NO donors reduces airway resistance (Aviado et al. 1968). NO relaxes tracheal and bronchial smooth muscle, activates guanylyl cyclase and increases cGMP level (Gruetter et al. 1989). Inhalation of NO in a concentration of 5-300 parts per million (ppm) reduces methacholineinduced bronchoconstriction in anesthetized guinea pigs (Dupuy et al. 1992). Adding $80 \mathrm{ppm}$ of NO to the inhaled air in anesthetized and mechanically ventilated rabbits avoided increase of airways reactivity to nebulized methacholine. In patients with COPD and healthy subjects inhalation of the same amount of NO had no effect, but it resulted in mild bronchodilation in patients with bronchial asthma (Högman et al. 1993). This insight into the history provides an evidence about the participation of endogenous and exogenous $\mathrm{NO}$ in regulation of bronchial smooth muscle tone.

Both parts of non-adrenergic non-cholinergic (NANC) nervous system play an important role in this regulation. The excitatory part (eNANC) mediates the contraction of airway smooth muscle while the inhibitory part (iNANC) elicits opposite response (Venugopalan et al. 1998, Widdicombe 1998). NO is one of the main neurotransmitters of iNANC system. It is produced by nNOS, which responds to the $\mathrm{Ca}^{2+}$ influx during nerve fibre depolarization. The terminals of these fibres are located in different distances from effector cells $(20 \mathrm{~nm}-2 \mu \mathrm{m})$. NO is released from the varicosities of these terminals and then diffuses through intercellular space to the effector cells (Khassawneh et al. 2002). Bronchodilatory response mediated by iNANC system is associated with increased cGMP levels in smooth muscle, suggesting modulation of bronchomotor tone through the NO/cGMP cascade (Widdicombe 1998).

The importance of NO as a neurotransmitter of iNANC system has been demonstrated by studies on isolated trachea of the guinea pigs and later in isolated preparations of human respiratory system ( $\mathrm{Li}$ and Rand 1991, Antosova and Strapkova 2013). Administration of NOS inhibitors in vitro significantly increased 
contraction mediated by cholinergic system after electrical or pharmacological stimulation (Di Maria et al. 2000). NO prevented bronchoconstriction induced by acetylcholine and other stimuli (Nijkamp and Folkerts 1997, Schuiling et al. 1998). NO inhalation caused bronchodilation in asthmatic patients (Folkerts and Nijkamp, 1998) and similarly, bronchodilation was observed after administration of NO donors (Di Maria et al. 2000).

In the regulation of bronchomotor tone the role of certain ion channels has been discussed (Ricciardolo 2003). L-type of calcium channels is the most important for the physiology of the airway smooth muscle. Its activity increases by treatment with substances with cholinergic effect and leads to the smooth muscle contraction (Fleischmann et al. 1996). The interaction of this type of channel and NO in the respiratory system is not fully understood. However, it is already known that these channels provide an optimal $\mathrm{Ca}_{\mathrm{i}}{ }^{2+}$ concentration for activation of constitutive NOS (Hall 2000).

Airway smooth muscle cells contain also potassium channels, particularly ATP-sensitive potassium channels. These are highly conductive channels dependent on calcium levels (Nijkamp and Folkerts, 1997). Opening of these channels contributes to the airway smooth muscle relaxation and hence bronchodilation. BKCa channels can be activated by NO directly, then through cGMP and finally via peroxynitrite. The role of these channels in NO-mediated signaling pathways was documented after bronchial relaxation induced by NO was blocked by administration of specific inhibitors of BKCa channels. Up to $50 \%$ of relaxation produced by NO might be mediated by these channels (Abderrahmane et al. 1998).

Significant role in the regulation of bronchomotor tone is done by the epithelium and mediators it produces. One of the relaxing factors released by epithelium is NO. It does not have a direct effect on baseline bronchial tone, but it reduces contractile response to cholinergic drugs, histamine, bradykinin, and $\mathrm{KCl}$ in the respiratory system of guinea pigs (Nijkamp et al. 1993). Contractile response to the action of various spasmogens increased after removal of the epithelium (Ricciardolo 2003).

Another important factor participating in the regulation of airway smooth muscle tone is arginase due to its competition with cNOS. Increased activity of endogenous arginase potentiates methacholine-induced bronchoconstriction through inhibition of $\mathrm{NO}$ by competing for the main substrate L-arginine. The activity of arginase is three-times higher in allergen-induced airway hyperreactivity than in physiological conditions (Meurs et al. 2002, Strapkova and Antosova 2011).

The airway smooth muscle tone is controlled via different humoral agents including metabolic products of arachidonic acid - prostaglandins and leukotrienes. Cyclooxygenase (COX) containing heme core is another possible target site for NO. The nature of the interaction between NO and COX depends on various factors such as the NO concentration, the iron valence in the enzyme, the redox state of the body and others. The interaction of COX vs. NOS seems to be important in the respiratory system and should be studied in details (Nijkamp and Folkerts 1997, Strapkova et al. 2006).

cGMP and cAMP as second messengers have an important role in the regulation of bronchomotor tone at the cellular level. Airway smooth muscle relaxation is mediated primarily by NO/cGMP pathways, wherein the cGMP is a second messenger of NO (Venugopalan et al. 1998). cAMP is a second messenger of the catecholamine-induced relaxation through $\beta 2$-adrenergic receptors. As a result, the activity of adenylate cyclase is increased and it catalyzes the conversion of ATP to cAMP. cAMP promotes the release and transport of $\mathrm{Ca}^{2+}$ out of the cell, resulting in bronchodilation. Hydrolysis of cGMP and cAMP is catalyzed by phosphodiesterases. cGMP acts on some of them as an inhibitor (PDE3) and activator for the other PDEs (PDE2, PDE5, PDE6), and thus it directly affects degradation of cAMP. This mechanism represents an important interaction of the NO/cGMP and cAMP signaling pathways in the respiratory system (Liaudet et al. 2000).

\section{The effect of NO on lung vasculature}

The role of NO in controlling the pulmonary circulation was studied by different approaches from pharmacological inhibition of NOS to utilization of knock-out animals for each of the three NOS isoforms (Moncada and Higgs 2006). While more recent studies suggested the role of NO in regulation of pulmonary vasculature tone under physiological circumstances, latest studies using knock-outs emphasize the importance of NO in hypoxia and other pathological circumstances (Dias-Junior et al. 2008).

Several mechanisms of NO-mediated vasodilation were suggested (Dweik 2001). NO is known to increase the activity of soluble guanylyl-cyclase most 
likely by the interaction with the heme moiety in the enzyme (Murad 1994). The enzyme catalyzes cGMP formation, which acts directly as a second messenger. As a result $\mathrm{Ca}_{\mathrm{i}}{ }^{2+}$ decrease and the sensitivity of the smooth muscle to $\mathrm{Ca}^{2+}$ reduces. NO-mediated vasodilation is inhibited by substances which block cGMP formation. Increased cGMP is also related to phosphorylation and activation of calcium-gated $\mathrm{K}^{+}$channel in vascular smooth muscles. $\mathrm{K}^{+}$channel activation by NO is inhibited by blockade of G-kinase, and the activating effect of NO on $\mathrm{K}^{+}$channels in pulmonary artery smooth muscle can be simulated by pharmacologic activation of G-kinases (Hampl 1995).

cGMP-dependent activation of $\mathrm{Ca}^{2+}$-activated $\mathrm{K}^{+}$channel seems to be another mechanism by which NO mediates vasodilation. Treatment with inhibitors of these channels can reverse relaxing effect of NO donors on lung vasculature (Rydberg et al. 1997). NO can also activate $\mathrm{K}^{+}$channels directly in the absence of cGMP or G-kinases (Bolotina et al. 1994). Interestingly, NO seems to modulate also the effect of angiotensin II on its receptors in lung vasculature (Ichiki et al. 1998).

In the studies with L-NAME and L-NMMA as NOS inhibitors it was demonstrated that endogenous NO production does not play an important role in keeping the low tone of pulmonary vessel wall in basal conditions regardless the route of administration or duration of exposure to NOS inhibitors (Phillipson et al. 2003). The animals presented significant systemic arterial hypertension, confirming the role of $\mathrm{NO}$ in maintaining vascular system homeostasis, however, NOS inhibitors had little or no effect on pulmonary artery pressure under the same circumstances. In contrast, in humans with infusion of high dose of NOS inhibitor the pulmonary artery pressure increased significantly (Fagan et al. 2001). Other studies have shown that only eNOS knockout animals present limited increase in pulmonary artery pressure. When these animals were exposed to hypoxia, in which pulmonary vessels respond with vasoconstriction, pulmonary hypertension was significantly higher than in controls. The data suggest that NO is not the sole mediator involved in low pulmonary vascular tone maintenance, however it is important in modulating the vasoconstriction response associated with hypoxia (Han et al. 2010). Release of eNOS/NO is largely reduced in chronic hypoxia as well (Adnot et al. 1991, Dinh-Xuan et al. 1991). Decreased expression and activity of eNOS in pulmonary endothelium relates to increased thickening of muscle layer in vascular wall and gradual vasoconstriction in pulmonary hypertension (Giaid and Saleh 1995), and decreased NO release by this isoform was also observed in pulmonary vessels in patients with COPD and cystic fibrosis (Voelkel et al. 2011).

Contrariwise, increased NO synthesis via endothelial isoform reduced increased systolic pressure in right ventricle caused by pulmonary hypertension. Overproduction of NO had positive effect in vascular remodeling in lung parenchyma and hypertrophy of the right ventricle caused by chronic hypoxia (Ozaki et al. 2001). There is inconsistent data about the effect of NO on bronchial circulation but NO seems to mediate vasodilation in the bronchial vessels.

The effect of NO on microvasculature and vascular permeability is not fully elucidated. NOS inhibitors prevent plasma leak in microvasculature elicited by substance $\mathrm{P}$ and leukotriene D4, but not after histamine. It indicates the importance of NO role in extravascular plasma leak caused by some inflammatory mediators (Kageyama et al. 1997). Simultaneously, the authors point out that plasma leak caused by these substances is increased in response to endogenous NO, especially in extrapulmonary, but not in intrapulmonary airways. This supports the concept of different regulation of protein influx in anatomically different parts of airways microvasculature (Ricciardolo 2003).

\section{NO and pulmonary surfactant}

Pulmonary surfactant is a lipid-protein complex which reduces surface tension at the air/liquid interface, thereby preventing lung collapse. About $80 \%$ of the alveolar surfactant are phospholipids, which are at least 50 different species and around $8-10 \%$ of surfactant molecules form specific proteins (Curstedt et al. 2013) In addition to the stabilization of the alveoli and small airways, surfactant prevents transudation of fluid into the alveoli, thereby preventing lung edema, it is involved in the local defense mechanisms, facilitates oxygen transport through the alveolar-capillary membrane and it has transport and barrier functions (Calkovska et al. 2005).

The mutual relationship between nitric oxide and surfactant was studied in different models. In isolated perfused rat lung model inhibition of cNOS and iNOS, as well as inhibition of cGMP and proteinkinase $\mathrm{G}$ reduced significantly surfactant secretion (Sun et al. 2003). In primary culture of alveolar type II cells, NO donor 
increased basal phosphatidylcholine (PC) secretion in a dose-dependent manner (Sun et al. 2003). The results suggest that NO may play an important role in lung surfactant secretion. Some studies emphasize the role of NO in pulmonary development. Expression of surfactant proteins SP-A, -B, and -C in the alveolar type II cells was not different between wild type (WT) and eNOS knockout mice. On the other hand, phosphatidylcholine (PC), the most abundant surfactant lipid component was reduced in broncho-alveolar lavage fluid from lungs of eNOS knock-out neonatal mice at birth in comparison with WT. The major and most surface-active phospholipid species, dipalmitoyl PC, was also significantly reduced in BAL fluid (Han et al. 2004). In SP-D and iNOS double knockout mice model the loss of alveoli and alterations of elastic properties of lung parenchyma with no changes in surfactant system where reported suggesting that surfactant homeostasis is mediated by different mechanisms (Knudsen et al. 2014).

Interestingly, surfactant was shown to have vasodilatory effect in alveolar capillary bed. This effect was inhibited by L-NAME, which means that the activation of NOS and NO production by alveolar epithelial cells is involved in surfactant-induced vasodilation (Yu et al. 1997). In contrast, recent study did not confirm the nitric oxide involvement in contractile response of airway smooth muscle to surfactant since treatment of isolated tracheal and bronchial tissue strips of guinea pigs with L-NAME did not prevent surfactantinduced muscle relaxation (Calkovska et al. 2015).

The ability of NO to control surfactant production by alveolar cells is used clinically, especially in premature infants (Lakshminrusimha et al. 2016). At low concentrations, NO has a potential to preserve surfactant function. Exposure of natural surfactant to NO (80 ppb, 4-12 h) prevents reduction in surface activity (Hallman and Bry 1996). On the other hand, high levels of NO are associated with free radical production which is enhanced by simultaneous oxygen therapy. On its own, nitric oxide acts as a potent inhibitor of the lipid peroxidation chain reaction by scavenging lipid peroxyl radicals. In addition, nitric oxide can also inhibit many potential initiators of lipid peroxidation, such as peroxidase enzymes. However, in the presence of superoxide, nitric oxide forms peroxynitrite, a powerful oxidant capable of initiating lipid peroxidation and oxidizing lipid soluble antioxidants (Hogg and Kalyanaraman 1999). Except lipid peroxidation, surfactant function can be also inhibited by NO-mediated damage to surfactant proteins (Rodriguez-Capote et al. 2006). More detailed insight in this clinically interesting issue of potential interactions of inhaled nitric oxide therapy with lung surfactant is beyond this review.

\section{NO and mucociliary transport}

Mucus production in the respiratory system is influenced neurally by autonomic cholinergic and NANC signaling and by complex network of mediators with stimulatory or inhibitory effects including neuropeptides, purines, enzymes and lipid mediators (Rogers 2007).

The effect of NO on mucus production by human airway submucosal glands was investigated using NOS inhibitors. Administration of L-NAME and L-MMMA reduced both methacholine- and bradykinininduced hypersecretion by isolated submucosal glands, and in addition, NO donor isosorbide dinitrate significantly increased submucosal gland secretion. This finding indicates that endogenous NO production has stimulating effect on submucosal glands secretion (Nagaki et al. 1995).

Stimulatory effect of other secretagogues was inhibited by preincubation of the cells with competitive NOS inhibitors. This indicates that mucin secretion was provoked via mechanisms involving intracellular production of NO as a critical signaling molecule (Adler et al. 1995). Endogenous NO stimulates the activity of respiratory submucosal glands which leads to subsequent increase in mucus production (Ricciardolo 2003, Bencova et al. 2012). Exogenous NO induced the MUC5AC mucin gene and protein through proteinkinase $\mathrm{C}$ pathways in human respiratory epithelial cells (Song et al. 2007).

Some studies indicate that NO does not play a role in controlling the airway submucosal glands under physiologic circumstances (Ballard and Spadafora 2007). In isolated rat trachea neither isosorbide dinitrate nor sodium nitroprusside, which liberate NO, were able to affect mucus secretion. Even zaprinast as a cGMP specific PDE5 (phosphodiesterase 5) inhibitor alone or in combination with NO donors had no effect (Ramnarine et al. 1996). The role of NO in mucus output control could become significant in pathological conditions after the expression of iNOS (Adler et al. 1995).

Nitric oxide affects also the ciliary motility. Stimulatory effect of cytokines on ciliary movement is suppressed by administration of NO synthases inhibitors and enhanced by administration of L-arginine, which proves the involvement of NO in ciliary motility. 
Together with increased ciliary motility, increased expression of eNOS in ciliary epithelium was reported (Jain et al. 1995). In patients with Kartagener syndrome, ciliary dysfunction is associated with impaired NO synthesis. Reduced NO synthesis is present in primary ciliary dyskinesia and cystic fibrosis, in which mucociliary clearance is impaired as well. The influence of NO on ciliary movement very likely involves phosphodiesterases modulation (Fischer et al. 1999) or modulation of ion channels activity (Duszyk 2001). From available literature it can be understood that nitric oxide acts as physiologic regulator of mucociliary clearance. Its metabolites increase tracheobronchial secretion (Jang et al. 2004) and the changes in its synthesis and activity can be an important component of pathophysiology of respiratory diseases related to changes in mucus secretion and mucociliary transport (Ricciardolo 2003).

\section{Conclusions}

Since the discovery of NO, numerous studies have been performed on cell cultures, animals and humans with the attempt to identify whether and how this small molecule interacts with various processes in respiratory system. Studies using NOS inhibitors, cGMP inhibitors, NO donors, or even new approaches using knock-out animals produced a huge pool of data, which is sometimes difficult to interpret due to the differences between species or methodological issues. Although there are conflicting results in some aspects of NO effects in the respiratory system, majority of data supports the positive and protective role of low concentration of $\mathrm{NO}$ produced by constitutive NOS, and potentially harmful effects of high concentrations of NO produced mainly by inductive NOS isoform. NO considerably regulates bronchial smooth muscle tone, lung vasculature and pulmonary blood flow, surfactant function, mucus output and other processes such as local host defense, antioxidant homeostasis and lung development.

\section{Conflict of Interest}

There is no conflict of interest.

\section{Acknowledgements}

This work was supported with Centre of Experimental and Clinical Respirology, ITMS code of Project 26220120004, which is co-financed from EU sources (ERDF), VEGA 1/0305/14 and APVV-15-0075.

\section{References}

ABDERRAHMANE A, SALVAIL D, DUMOULIN M, GARON J, CADIEUX A, ROUSSEAU E: Direct activation of $\mathrm{K}(\mathrm{Ca})$ channel in airway smooth muscle by nitric oxide: involvement of a nitrothiosylation mechanism? $\mathrm{Am}$ J Respir Cell Mol Biol 19: 485-497, 1998.

ADLER KB, FISCHER BM, LI H, CHOE NH, WRIGHT DT: Hypersecretion of mucin in response to inflammatory mediators by guinea pig tracheal epithelial cells in vitro is blocked by inhibition of nitric oxide synthase. $\mathrm{Am}$ J Respir Cell Mol Biol_13: 526-530, 1995.

ADNOT S, RAFFESTIN B, EDDAHIBI S, BRAQUET P, CHABRIER PE: Loss of endothelium-dependent relaxant activity in the pulmonary circulation of rats exposed to chronic hypoxia. J Clin Invest 87: 155-162, 1991.

AIZAWA H: Role of nitric oxide in airway inflammation and hyperresponsiveness in bronchial asthma. Allergol Int 48: 25-30, 1999.

ANTOSOVA M, STRAPKOVA A: L-arginine supplementation and experimental airway hyperreactivity. Adv Exp Med Biol 756: 81-89, 2013.

ANTOSOVA M, STRAPKOVA A: Study of the interaction of glutamatergic and nitrergic signalling in conditions of the experimental airways hyperreactivity. Pharmacol Rep 65: 650-657, 2013.

ANTOSOVA M, PLEVKOVA J, STRAPKOVA A, BUDAY T: Nitric oxide-important messenger in human body. Open J Mol Integr Physiol 2: 98-106, 2012.

ANTOSOVA M, STRAPKOVA A, MIKOLKA P, MOKRY J, MEDVEDOVA I, MOKRA D: The influence of L-NAME on iNOS expression and markers of oxidative stress in allergen-induced airway hyperreactivity. $A d v$ Exp Med Biol 838: 1-10, 2015.

AVIADO DM, FOLLE LE, BELLET S: Cardiopulmonary effects of glyceryl trinitrate and isosorbide dinitrate. Cardiologia 52: 287-303, 1968. 
BALLARD ST, SPADAFORA D: Fluid secretion by submucosal glands of the tracheobronchial airways. Respir Physiol Neurobiol 159: 271-277, 2007.

BENCOVA A, VIDAN J, ROZBORILOVA E, KOCAN I: The impact of hypertonic saline inhalation on mucociliary clearance and nasal nitric oxide. J Physiol Pharmacol 63: 309-313, 2012.

BLACKFORD JA, ANTONINI JM, CASTRANOVA V, DEY RD: Intratracheal instillation of silica up-regulates inducible nitric oxide synthase gene expression and increases nitric oxide production in alveolar macrophages and neutrophils. Am J Respir Cell Mol Biol 11: 426-431, 1994.

BOLOTINA VM, NAJIBI S, PALACINO JJ, PAGANO PJ, COHEN RA: Nitric oxide directly activates calciumdependent potassium channels in vascular smooth muscle. Nature 368: 850-853, 1994.

CALKOVSKA A, SOME M, LINDERHOLM B, JOHANSSON J, CURSTEDT T, ROBERTSON B: Biophysical and physiological properties of porcine surfactant enriched with polymyxin B. Biol Neonate 88: 101-108, 2005.

CALKOVSKA A, UHLIAROVA B, JOSKOVA M, FRANOVA S, KOLOMAZNIK M, CALKOVSKY V, SMOLAROVA S: Pulmonary surfactant in the airway physiology: A direct relaxing effect on the smooth muscle. Respir Physiol Neurobiol 209: 95-105, 2015.

CARVAJAL JA, GERMAIN AM, HUIDOBRO-TORO JP, WEINER CP: Molecular mechanism of cGMP-mediated smooth muscle relaxation. $J$ Cell Physiol 184: 409-420, 2000.

CHARLES A: Nitric oxide pumps up calcium signalling. Nat Cell Biol 1: E193-E195, 1999.

COX RA, JACOB S, OLIVERAS G, MURAKAMI K, ENKHBAATAR P, TRABER L, SCHMALSTIEG FC, HERNDON DN, TRABER DL, HAWKINS HK: Pulmonary expression of nitric oxide synthase isoforms in sheep with smoke inhalation and burn injury. Exp Lung Res 35: 104-118, 2009.

CUCCHIARO G, TATUM AH, BROWN MC, CAMPORESI EM, DAUCHER JW, HAKIM TS: Inducible nitric oxide synthase in the lung and exhaled nitric oxide after hyperoxia. Am J Physiol 277: L636-L644, 1999.

CURSTEDT T, CALKOVSKA A, JOHANSSON J. New generation synthetic surfactants. Neonatology 103: 327-330, 2013.

Di MARIA GU, SPICUZZA L, MISTRETTA A, MAZZARELLA G: Role of endogenous nitric oxide in asthma. Allergy 55 (Suppl 61): 31-35, 2000.

DIAS-JUNIOR CA, CAU SB, TANUS-SANTOS JE: Role of nitric oxide in the control of the pulmonary circulation: physiological, pathophysiological, and therapeutic implications. (In Portuguese) J Bras Pneumol 34: 412-419, 2008.

DINH-XUAN AT, HIGENBOTTAM TW, CLELLAND CA, PEPKE-ZABA J, CREMONA G, BUTT AY, LARGE SR, WELLS FC, WALLWORK J: Impairment of endothelium-dependent pulmonary-artery relaxation in chronic obstructive lung disease. N Engl J Med 324: 1539-1547, 1991.

DJAKOW J, O’CALLAGHAN C: Primary ciliary dyskinesia. Breathe 10: 122-133, 2014.

DOMENICO R: Pharmacology of nitric oxide: molecular mechanisms and therapeutic strategies. Curr Pharm Des 10: 1667-1676, 2004.

DUPUY PM, SHORE SA, DRAZEN JM, FROSTELL C, HILL WA, ZAPOL WM: Bronchodilator action of inhaled nitric oxide in guinea pigs. J Clin Invest 90: 421-428, 1992.

DUSZYK M: Regulation of anion secretion by nitric oxide in human airway epithelial cells. Am J Physiol Lung Cell Mol Physiol 281: L450-L457, 2001.

DWEIK RA: The promise and reality of nitric oxide in the diagnosis and treatment of lung disease. Cleve Clin J Med 68: 486, 488, 490, 493, 2001.

FAGAN KA, MORRISSEY B, FOUTY BW, SATO K, HARRAL JW, MORRIS KG, HOEDT-MILLER M, VIDMAR S, MCMURTRY IF, RODMAN DM: Upregulation of nitric oxide synthase in mice with severe hypoxia-induced pulmonary hypertension. Respir Res 2: 306-313, 2001.

FISCHER BM, ROCHELLE LG, VOYNOW JA, AKLEY NJ, ADLER KB: Tumor necrosis factor-alpha stimulates mucin secretion and cyclic GMP production by guinea pig tracheal epithelial cells in vitro. Am J Respir Cell Mol Biol 20: 413-422, 1999.

FLEISCHMANN BK, WANG YX, PRING M, KOTLIKOFF MI: Voltage-dependent calcium currents and cytosolic calcium in equine airway myocytes. $J$ Physiol 492: 347-358, 1996. 
FLEMING I, BUSSE R: Molecular mechanisms involved in the regulation of the endothelial nitric oxide synthase. $A m$ J Physiol Regul Integr Comp Physiol 284: R1-R12, 2003.

FOLKERTS G, NIJKAMP FP: Airway epithelium: more than just a barrier! Trends Pharmacol Sci 19: 334-341, 1998.

FÖRSTERMANN U, SESSA WC: Nitric oxide synthases: regulation and function. Eur Heart J 33: 829-837, 2012.

FURCHGOTT RF, ZAWADZKI JV: The obligatory role of endothelial cells in the relaxation of arterial smooth muscle by acetylcholine. Nature 288: 373-376, 1980.

GIAID A, SALEH D: Reduced expression of endothelial nitric oxide synthase in the lungs of patients with pulmonary hypertension. $N$ Engl J Med 333: 214-221, 1995.

GILCHRIST M, SAVOIE M, NOHARA O, WILLS FL, WALLACE JL, BEFUS AD: Nitric oxide synthase and nitric oxide production in in vivo-derived mast cells. J Leukoc Biol 71: 618-624, 2002.

GOTOH T, ARAKI M, MORI M: Chromosomal localization of the human arginase II gene and tissue distribution of its mRNA. Biochem Biophys Res Commun 233, 487-491, 1997.

GRASEMANN H, STORM VAN'S GRAVESANDE K, BUSCHER R, DRAZEN JM, RATJEN F: Effects of sex and of gene variants in constitutive nitric oxide synthases on exhaled nitric oxide. Am J Respir Crit Care Med 167: 1113-1116, 2003.

GRIFFITH OW, STUEHR DJ: Nitric oxide synthases: properties and catalytic mechanism. Annu Rev Physiol 57: 707-736, 1995.

GRUETTER CA, CHILDERS CE, BOSSERMAN MK, LEMKE SM, BALL JG, VALENTOVIC MA: Comparison of relaxation induced by glyceryl trinitrate, isosorbide dinitrate, and sodium nitroprusside in bovine airways. $\mathrm{Am}$ Rev Respir Dis 139: 1192-1197, 1989.

HALL IP: Second messengers, ion channels and pharmacology of airway smooth muscle. Eur Respir J 15: 1120-1127, 2000.

HALLMAN M, BRY K: Nitric oxide and lung surfactant. Semin Perinatol 20: 173-185, 1996.

HAMAD AM, CLAYTON A, ISLAM B, KNOX AJ: Guanylyl cyclases, nitric oxide, natriuretic peptides, and airway smooth muscle function. Am J Physiol Lung Cell Mol Physiol 285: L973-L983, 2003.

HAMPL V: Nitric oxide in the pulmonary circulation during hypoxia. Anaesthesia 50: 264-265, 1995.

HAN F, LU YM, HASEGAWA H, KANAI H, HACHIMURA E, SHIRASAKI Y, FUKUNAGA K: Inhibition of dystrophin breakdown and endothelial nitric-oxide synthase uncoupling accounts for cytoprotection by 3-[2-[4(3-Chloro-2-methylphenyl)-1-piperazinyl] ethyl]-5,6-dimethoxy-1-(4-imidazolylmethyl)-1H-indazole dihydrochloride 3.5 hydrate (DY-9760e) in left ventricular hypertrophied Mice. J Pharmacol Exp Ther 332: 421-428, 2010.

HAN RN, BABAEI S, ROBB M, LEE T, RIDSDALE R, ACKERLEY C, POST M, STEWART DJ: Defective lung vascular development and fatal respiratory distress in endothelial NO synthase-deficient mice: a model of alveolar capillary dysplasia? Circ Res 94: 1115-1123, 2004.

HARRISON DG: Cellular and molecular mechanisms of endothelial cell dysfunction. $J$ Clin Invest 100: 2153-2157, 1997.

HÖGMAN M, FROSTELL C, ARNBERG H, HEDENSTIERNA G: Inhalation of nitric oxide modulates methacholineinduced bronchoconstriction in the rabbit. Eur Respir J 6: 177180, 1993.

HOGG N, KALYANARAMAN B: Nitric oxide and lipid peroxidation. Biochim Biophys Acta 1411: 378-384, 1999.

ICHIKI T, USUI M, KATO M, FUNAKOSHI Y, ITO K, EGASHIRA K, TAKESHITA A: Downregulation of angiotensin II type 1 receptor gene transcription by nitric oxide. Hypertension 31: 342-346, 1998.

JAIN B, RUBINSTEIN I, ROBBINS RA, SISSON JH: TNF-alpha and IL-1 beta upregulate nitric oxide-dependent ciliary motility in bovine airway epithelium. Am J Physiol 268: L911-L917, 1995.

JANG AS, CHOI IS, LEE JU, PARK SW, LEE JH, PARK CS: Changes in the expression of NO synthase isoforms after ozone: the effects of allergen exposure. Respir Res 5: 5, 2004.

JIA Y, ZACOUR M, TOLLOCZKO B, MARTIN JG: Nitric oxide synthesis by tracheal smooth muscle cells by a nitric oxide synthase-independent pathway. Am J Physiol 275: L895-L901, 1998.

KAGEYAMA N, MIURA M, ICHINOSE M, TOMAKI M, ISHIKAWA J, OHUCHI Y, ENDOH N, SHIRATO K: Role of endogenous nitric oxide in airway microvascular leakage induced by inflammatory mediators. Eur Respir J 10: 13-19, 1997. 
KAWAMOTO H, TAKUMIDA M, TAKENO S, WATANABE H, FUKUSHIMA N, YAJIN K: Localization of nitric oxide synthase in human nasal mucosa with nasal allergy. Acta Otolaryngol 539 (Suppl): 65-70, 1998.

KAŽIĆ T, GOJKOVIĆ-BUKARICA L: Ion channels and drug development. Focus on potassium channels and their modulators. Facta Univ 6: 23-30, 1999.

KHARITONOV SA, LUBEC G, LUBEC B, HJELM M, BARNES PJ: L-arginine increases exhaled nitric oxide in normal human subjects. Clin Sci (Lond) 88: 135-139, 1995.

KHASSAWNEH MY, DRESHAJ IA, LIU S, CHANG C-H, HAXHIU MA, MARTIN RJ: Endogenous nitric oxide modulates responses of tissue and airway resistance to vagal stimulation in piglets. $J$ Appl Physiol (1985) 93: 450-456, 2002.

KLENIEWSKA P, GORĄCA A. Influence of endothelin 1 receptor blockers and a nitric oxide synthase inhibitor on reactive oxygen species formation in rat lungs. Physiol Res 65: 789-798, 2016.

KNUDSEN L, ATOCHINA-VASSERMAN EN, GUO CJ, SCOTT PA, HAENNI B, BEERS MF, OCHS M, GOW AJ: NOS2 is critical to the development of emphysema in Sftpd deficient mice but does not affect surfactant homeostasis. PLoS One 9: e85722, eCollection 2014.

KONE BC: Localization and regulation of nitric oxide synthase isoforms in the kidney. Semin Nephrol 19: 230-241, 1999.

KOPINCOVA J, CALKOVSKA A: Meconium-induced inflammation and surfactant inactivation: specifics of molecular mechanisms. Pediatr Res 79: 514-521, 2016.

LACZA Z, SNIPES JA, ZHANG J, HORVÁTH EM, FIGUEROA JP, SZABÓ C, BUSIJA DW: Mitochondrial nitric oxide synthase is not eNOS, nNOS or iNOS. Free Radic Biol Med 35: 1217-1228, 2003.

LAKSHMINRUSIMHA S, KONDURI GG, STEINHORN RH: Considerations in the management of hypoxemic respiratory failure and persistent pulmonary hypertension in term and late preterm neonates. J Perinatol 36 (Suppl 2): S12-S19, 2016.

LI CG, RAND MJ: Evidence that part of the NANC relaxant response of guinea-pig trachea to electrical field stimulation is mediated by nitric oxide. Br J Pharmacol 102: 91-94, 1991.

LIAUDET L, SORIANO FG, SZABÓ C: Biology of nitric oxide signaling. Crit Care Med 28: N37-N52, 2000.

MEURS H, MAARSINGH H, ZAAGSMA J: Arginase and asthma: novel insights into nitric oxide homeostasis and airway hyperresponsiveness. Trends Pharmacol Sci 24: 450-455, 2003.

MEURS H, MCKAY S, MAARSINGH H, HAMER MAM, MACIC L, MOLENDIJK N, ZAAGSMA J: Increased arginase activity underlies allergen-induced deficiency of cNOS-derived nitric oxide and airway hyperresponsiveness. Br J Pharmacol 136: 391-398, 2002.

MOKRY J, MOKRA D: Immunological aspects of phosphodiesterase inhibition in the respiratory system. Respir Physiol Neurobiol 187: 11-17, 2013.

MONCADA S, HIGGS EA: The discovery of nitric oxide and its role in vascular biology. Br J Pharmacol 147 (Suppl 1): S193-S201, 2006.

MORGAN L: Nitric oxide: a challenge to chiropractic. J Can Chiropr Assoc 44: 40, 2000.

MORRIS SM: Regulation of enzymes of the urea cycle and arginine metabolism. Annu Rev Nutr 22: 87-105, 2002.

MURAD F: The nitric oxide-cyclic GMP signal transduction system for intracellular and intercellular communication. Recent Prog Horm Res 49: 239-248, 1994.

NAGAKI M, SHIMURA MN, IROKAWA T, SASAKI T, SHIRATO K: Nitric oxide regulation of glycoconjugate secretion from feline and human airways in vitro. Respir Physiol 102: 89-95, 1995.

NIJKAMP FP, FOLKERTS G: Nitric oxide: initiator and modulator. Clin Exp Allergy 27: 347-350, 1997.

NIJKAMP FP, VAN DER LINDE HJ, FOLKERTS G: Nitric oxide synthesis inhibitors induce airway hyperresponsiveness in the guinea pig in vivo and in vitro. Role of the epithelium. Am Rev Respir Dis 148: 727-734, 1993.

OZAKI M, KAWASHIMA S, YAMASHITA T, OHASHI Y, RIKITAKE Y, INOUE N, HIRATA KI, HAYASHI Y, ITOH H, YOKOYAMA M: Reduced hypoxic pulmonary vascular remodeling by nitric oxide from the endothelium. Hypertension 37: 322-327, 2001.

PALMER RM, FERRIGE AG, MONCADA S: Nitric oxide release accounts for the biological activity of endotheliumderived relaxing factor. Nature 327: 524526, 1987. 
PECHKOVSKY DV, ZISSEL G, GOLDMANN T, EINHAUS M, TAUBE C, MAGNUSSEN H, SCHLAAK M, MÜLLER-QUERNHEIM J: Pattern of NOS2 and NOS3 mRNA expression in human A549 cells and primary cultured AEC II. Am J Physiol Lung Cell Mol Physiol 282: L684-L692, 2002.

PHILLIPSON M, HENRIKSNÄS J, HOLSTAD M, SANDLER S, HOLM L: Inducible nitric oxide synthase is involved in acid-induced gastric hyperemia in rats and mice. Am J Physiol Gastrointest Liver Physiol 285: G154-G162, 2003.

PRADO CM, MARTINS MA, TIBÉRIO IFLC: Nitric oxide in asthma physiopathology. ISRN Allergy 2011: 832560, 2011.

PÚZSEROVÁ A, KOPINCOVÁ J, BERNÁTOVÁ I: Endothelial (dys) function in the experimental model of primary hypertension. (In Slovak) Cesk Fysiol 59: 4-14, 2010.

RAMNARINE SI, KHAWAJA AM, BARNES PJ, ROGERS DF: Nitric oxide inhibition of basal and neurogenic mucus secretion in ferret trachea in vitro. Br J Pharmacol 118: 998-1002, 1996.

RICCIARDOLO FLM: Multiple roles of nitric oxide in the airways. Thorax 58: 175-182, 2003.

RICCIARDOLO FLM, STERK PJ, GASTON B, FOLKERTS G: Nitric oxide in health and disease of the respiratory system. Physiol Rev 84: 731-765, 2004.

RODRÍGUEZ-CAPOTE K, MANZANARES D, HAINES T, POSSMAYER F: Reactive oxygen species inactivation of surfactant involves structural and functional alterations to surfactant proteins SP-B and SP-C. Biophys $J$ 90: 2808-2821, 2006.

ROGERS DF: Physiology of airway mucus secretion and pathophysiology of hypersecretion. Respir Care 52: 1134-1146; discussion 1146-1149, 2007.

ROMANSKA HM, POLAK JM, COLEMAN RA, JAMES RS, HARMER DW, ALLEN JC, BISHOP AE: iNOS gene upregulation is associated with the early proliferative response of human lung fibroblasts to cytokine stimulation. J Pathol 197: 372-379, 2002.

RYDBERG IGMJ, ANDERSSON RGG, GRENEGÅRD M: Effects of the nitric oxide-donor, GEA 3175, on guineapig airways. Eur J Pharmacol 329: 175-180, 1997.

SAJEEV C, SRIDHAR N, VEERANJANEYULU A: Nitric oxide: concepts, current perspectives and future therapeutic implications. Indian J Pharmacol 30: 351, 1998.

SCHUILING M, MEURS H, ZUIDHOF AB, VENEMA N, ZAAGSMA J: Dual action of iNOS-derived nitric oxide in allergen-induced airway hyperreactivity in conscious, unrestrained guinea pigs. Am J Respir Crit Care Med 158: 1442-1449, 1998.

SILKOFF PE, ROBBINS RA, GASTON B, LUNDBERG JO, TOWNLEY RG: Endogenous nitric oxide in allergic airway disease. $J$ Allergy Clin Immunol 105: 438-448, 2000.

SONG JS, KANG CM, YOO MB, KIM SJ, YOON HK, KIM YK, KIM KH, MOON HS, PARK SH: Nitric oxide induces MUC5AC mucin in respiratory epithelial cells through PKC and ERK dependent pathways. Respir Res 8: $28,2007$.

STRAPKOVA A, ANTOSOVA M: Competition of NO synthases and arginase in the airways hyperreactivity. Gen Physiol Biophys 30: 75-83, 2011.

STRAPKOVA A, ANTOSOVA M, NOSALOVA G. Interaction between nitric oxide and prostanoids in the respiratory system. Bratisl Lek Listy 107: 52-57, 2006.

STUART-SMITH K, WARNER DO, JONES KA: The role of cGMP in the relaxation to nitric oxide donors in airway smooth muscle. Eur J Pharmacol 341: 225-233, 1998.

SU Y, COUCH M, BLOCK ER: Substrate inhibition of nitric oxide synthase in pulmonary artery endothelial cells in culture. Nitric Oxide Biol Chem 1: 469-475, 1997.

SUN P, WANG J, MEHTA P, BECKMAN DL, LIU L: Effect of nitric oxide on lung surfactant secretion. Exp Lung Res 29: 303-314, 2003.

VALLANCE P: Nitric oxide. Biol Lond Engl 48: 153-158, 2001.

VENUGOPALAN CS, KRAUTMANN MJ, HOLMES EP, MAHER TJ: Involvement of nitric oxide in the mediation of NANC inhibitory neurotransmission of guinea-pig trachea. J Auton Pharmacol 18: 281-286, 1998.

VERCELLI D: Arginase: marker, effector, or candidate gene for asthma? J Clin Invest 111: 1815-1817, 2003. 
VOELKEL NF, GOMEZ-ARROYO J, MIZUNO S: COPD/emphysema: The vascular story. Pulm Circ 1: 320-326, 2011.

WARD JK, BARNES PJ, TADJKARIMI S, YACOUB MH, BELVISI MG: Evidence for the involvement of cGMP in neural bronchodilator responses in humal trachea. $J$ Physiol 483: 525-536, 1995.

WARNER RL, PAINE R, CHRISTENSEN PJ, MARLETTA MA, RICHARDS MK, WILCOXEN SE, WARD PA: Lung sources and cytokine requirements for in vivo expression of inducible nitric oxide synthase. Am J Respir Cell Mol Biol 12: 649-661, 1995.

WIDDICOMBE JG: Autonomic regulation. i-NANC/e-NANC. Am J Respir Crit Care Med 158: S171-S175, 1998.

WU G, MORRIS SM: Arginine metabolism: nitric oxide and beyond. Biochem J 336: 1-17, 1998.

XUE C, BOTKIN SJ, JOHNS RA: Localization of endothelial NOS at the basal microtubule membrane in ciliated epithelium of rat lung. J Histochem Cytochem 44: 463-471, 1996.

YU XQ, FEET BA, MOEN A, CURSTEDT T, SAUGSTAD OD: Nitric oxide contributes to surfactant-induced vasodilation in surfactant-depleted newborn piglets. Pediatr Res 42: 151-156, 1997. 